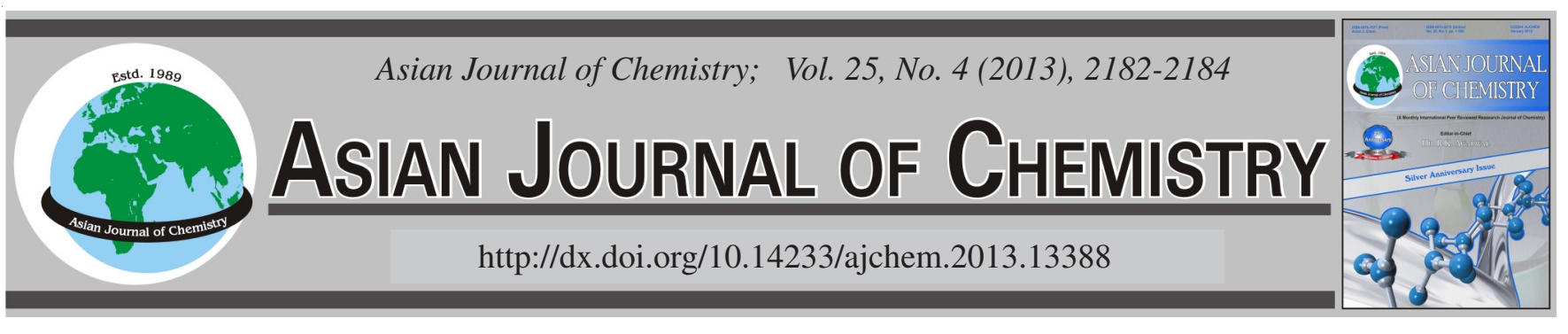

\title{
Synergistic Effect of Organic Silicon Surfactant in Chemical Control of the New Invasive Mealybug, Phenacoccus solenopsis Tinsley (Hemiptera: Pseudococcidae) in China
}

\author{
Jun HuANG ${ }^{1, \dagger}$ and JuAn Zhang ${ }^{2,+, *}$ \\ ${ }^{1}$ Flower Research and Development Centre, Zhejiang Academy of Agricultural Sciences, Hangzhou 311202, P.R. China \\ ${ }^{2}$ Institute of Insect Sciences, Zhejiang University, Hangzhou 310029, P.R. China \\ $†$ Both authors contributed equally \\ *Corresponding author: Fax: +86 571 82736790; Tel: +86 571 82736790; E-mail: junhuang1981@ yahoo.cn \\ (Received: 5 January 2012; \\ Accepted: 17 October 2012) \\ AJC-12308

\begin{abstract}
The mealybug Phenacoccus solenopsis has been recently reported as one of the most serious invasive insect pests in Asian countries, such as Pakistan, India, Thailand, Australia and China. However, a safe and effective method of chemical control for the solenopsis mealybug is imminent. This study investigated the synergistic effects of $0.03,0.06$ and $0.09 \%$ organic silicon surfactant on the $10 \%$ imidacloprid WP against the mortalities of different instars nymph and adult female of the solenopsis mealybug. Results showed that both concentrations the suitable concentration of organic silicon surfactant adding to imidacloprid was $0.06 \%$. With the treatment of mixtures of $50 \mathrm{mg} \mathrm{L}^{-1}$ imidacloprid with $0.06 \%$ organic silicon, the mortality of the solenopsis mealybug was up to $100 \%$ after $15 \mathrm{~d}$ on the plants of Torenia fournieri.
\end{abstract} \\ of organic silicon surfactant and insect stages had significantly effects on the mortality of the solenopsis mealybug. In addition, we found \\ Key Words: Phenacoccus solenopsis, Imidacloprid, Organic silicon, Mortality, Chemical control.
}

\section{INTRODUCTION}

Organic silicon chemistries are one kind of key organometallic compounds (R-Si), which have many uses in materials science and in metallurgy. Organic silicon product structure contains both organic groups and inorganic structures, this special composition and molecular structure makes it sets the organic characteristics and inorganic functions. One most outstanding performance of organic silicon in agriculture is the low surface tension and surface energy ${ }^{1,2}$. That is the reason that organic silicon always been added to insecticides and herbicides for increasing the control efficiency in the fields.

The solenopsis mealybug, Phenacoccus solenopsis Tinsley (Hemiptera: Pseudococcidae) is an invasive insect pest that is new to China and described originally from USA in $1898^{3}$, suggesting it is native there. So far, it is known to occur in some Asian countries, such as Pakistan, India, Thailand and Australia $^{4-7}$. In India, $P$. solenopsis infestation was recorded on $G$. hirsutum from nine cotton-growing states ${ }^{8}$. In the cotton producing area of Pakistan (totaling 8.0 million acres), over 150,000 acres has been seriously damaged by $P$. solenopsis ${ }^{9}$. If $P$. solenopsis cannot be controlled effectively, Wang et al. ${ }^{10}$ forecasted that the losses in cotton yield in 2008/2009 would be 1.4 million tons in China, 1.12 million tons in India and
0.48 million tons in Pakistan. However, it is difficult to control this pest with single chemical insecticides. Some key reasons for the phenomenon include: 1) the mealybugs possesses a waxy coating that protects them from insecticides and natural mortality factors; 2) they have the ability to hide in soil cracks and crevices; 3 ) they have a high reproductive rate and serious overlapped generations. A safe and effective method of chemical control for this invasive mealybug is imminent.

In this study, we examined the synergistic effects of different concentration of organic silicon on the imidacloprid against the mortality of different instars nymph and adult females of the solenopsis mealybug under laboratory condition. In addition, we also tested the effect of suitable concentration of organic silicon against the mortality of solenopsis mealybug in the field.

\section{EXPERIMENTAL}

The solenopsis mealybug was obtained from Portulaca grandiflora (Caryophyllales: Portulacaceae) at the suburbs of Hangzhou, Zhejiang province, China and fed on Torenia fournieri (Scrophulariales: Scrophulariaceae) in laboratory. The experiments insect cultures were maintained at constant temperature $\left(26 \pm 1{ }^{\circ} \mathrm{C}\right), 14 \mathrm{~L}: 10 \mathrm{D}$ photoperiod and $65 \pm 5 \%$ relative humidity. $10 \%$ imidacloprid WP (supplied by Nanjing 
Baofeng Pesticides Factory) and organic silicon surfactant (supplied by Shandong Tianda Bio-pharmaceutics Co. Ltd.) were chosen in test.

Laboratory test: The leaves of T. fournieri carrying the solenopsis mealybug were collected carefully using a scissors. About 15 head solenopsis mealybug of the same instars $\left(1^{\text {st }}\right.$ instar nymph, $2^{\text {nd }}$ instar nymph, $3^{\text {rd }}$ instar nymph and adult female, respectively) were maintained on one leaf. Then putting the treated leaf in the culture dish $(9 \mathrm{~cm}$ in diameter $)$ and swaddling the leafstalk using humid pledget.

The concentration of $50 \mathrm{mg} \mathrm{L}^{-1}$ of $10 \%$ imidacloprid WP was made up with distilled water. Then 0.03, 0.06 and $0.09 \%$ organic silicon surfactants were added to the imidacloprid solution, respectively; the imidacloprid solution without organic silicon surfactant as the control. The mixture and imidacloprid liquid was sucked up by liquid-transfering gun (Dragon, 20-200 $\mu \mathrm{L}$ ). The mixture liquid was spotted slowly on the each body of the solenopsis mealybugs; $300 \mu \mathrm{L}$ in each replicate and 4 replicates for each treatment. The mortality of solenopsis mealybug in each treatment was observed and noted by direct counting after $5 \mathrm{~d}$.

Field test: This part of test was conducted at the garden spot in Zhejiang Academy of Agricultural Sciences. The concentration of $50 \mathrm{mg} \mathrm{L}^{-1}$ of $10 \%$ imidacloprid WP was made up with distilled water; then adding $0.06 \%$ organic silicon surfactants to the imidacloprid solution. The imidacloprid treated without organic silicon surfactant as another treatment and the solenopsis mealybug treated with distilled water as the control. The plants of $T$. fournieri (cultivated in the pots) growing coherently and carrying the solenopsis mealybugs were chosen in the test. Each treatment was replicated 3 times, one plant (pot) of $T$. fournieri as each replicate. The number of solenopsis mealybug in the plants of T. fournieri was counted before the test. Then the mortality of solenopsis mealybug in each treatment was observed and noted by direct counting after $1 \mathrm{~d}, 3 \mathrm{~d}, 5 \mathrm{~d}, 7 \mathrm{~d}, 9 \mathrm{~d}$ and $15 \mathrm{~d}$.

Statistical analysis: The mortalities of different instars nymph and adult females of solenopsis mealybug with different concentrations of organic silicon surfactant were compared by Two-way ANOVA and followed by Fisher's LSD multiple comparison tests. All the statistical analyses were conducted by utilizing the Statistical Package for Social Sciences, version 14.0.

\section{RESULTS AND DISCUSSION}

Both concentrations of organic silicon surfactant and insect stages had significantly effects on the mortality of solenopsis mealybug (Table-1). The mortalities of solenopsis mealybug were up to $100 \%$ when the concentrations of organic silicon surfactant were $0.06 \%$ and $0.09 \%$. Similar phenomenon was found in the treatment of $0.03 \%$ organic silicon surfactant against the $1^{\text {st }}$ instars nymph of solenopsis mealybug. Thus, the mortalities of $2^{\text {nd }}$ instars nymph, $3^{\text {rd }}$ instars nymph and adult female of solenopsis mealybug were $90.0,82.5$ and $67.5 \%$, respectively, with the treatment of 0.03 $\%$ organic silicon surfactant (Fig. 1). According to our observation, the leaves of $T$. fournieri were damaged by the mixtures of $50 \mathrm{mg} \mathrm{L}^{-1}$ imidacloprid with $0.09 \%$ organic silicon surfactant, indicating the higher concentration of organic silicon surfactant unsuitable for the plants. Therefore, we conducted the further test with the treatment of $0.06 \%$ organic silicon surfactant in the field.

TABLE-1

TWO-WAY ANALYSIS OF VARIANCE TESTING THE EFFECTS

OF ORGANIC SILICON ON THE IMIDACLOPRID AGAINST THE

MORTALITIES OF DIFFERENT INSTARS NYMPH AND ADULT FEMALE OF THE SOLENOPSIS MEALYBUG

\begin{tabular}{lcccc}
\hline Effect & $\begin{array}{c}\text { Degrees of } \\
\text { freedom }\end{array}$ & $\begin{array}{c}\text { Mean } \\
\text { squares }\end{array}$ & $F$ & $P$ \\
\hline Instars (A) & 3 & 1349.63 & 36.14 & $<0.001$ \\
Organic silicon & 3 & 4303.16 & 115.21 & $<0.001$ \\
concentrations (B) & 9 & 514.63 & 13.78 & $<0.001$ \\
A $\times$ B & 48 & 37.35 & & \\
Residual & 63 & 371.16 & & \\
\hline Total & & & & \\
\hline
\end{tabular}

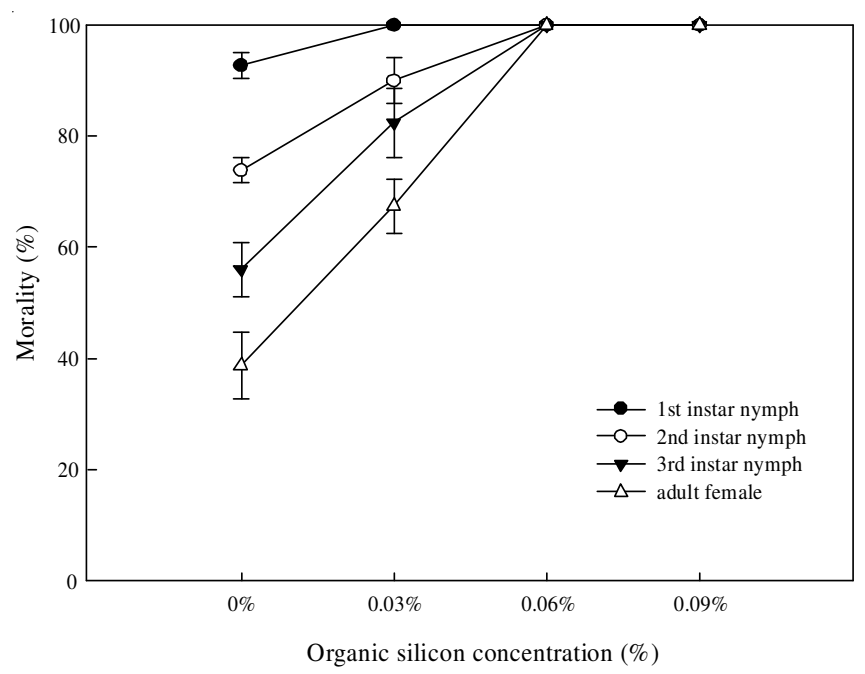

Fig. 1. Control effects of the mixtures of $50 \mathrm{mg} \mathrm{L}^{-1}$ imidacloprid with different concentrations of organic silicon against different instars nymph and adult females of the solenopsis mealybug

With the treatment of $0.06 \%$ organic silicon surfactant, the mortality of solenopsis mealybug was up to $100 \%$ after $15 \mathrm{~d}$ in the field (Fig. 2). But the mortality of solenopsis mealybug had no significant change without $0.06 \%$ organic silicon surfactant. In addition, we found the number of solenopsis mealybug increased by $c a .45 \%$ with the control. So, the mixtures of $50 \mathrm{mg} \mathrm{L}^{-1}$ imidacloprid with $0.06 \%$ organic silicon surfactant had significant control effect on the solenopsis mealybug in our test. Two reasons may be explained for the results. First, the organic silicon surfactant increases the time of insecticide staying on the plant. Second, the organic silicon surfactant could change the permeability of integument of the solenopsis mealybug. Certainly, we should make further study on the mechanisms of organic silicon surfactant on the integument of the invasive mealybug in the future.

\section{ACKNOWLEDGEMENTS}

Our study was supported by the Special Fund for Agroscientific Research in the Public Interest (No. 201103026), the Key Scientific Innovation Project of Zhengjiang, China (NO. 2011R50034-14). 


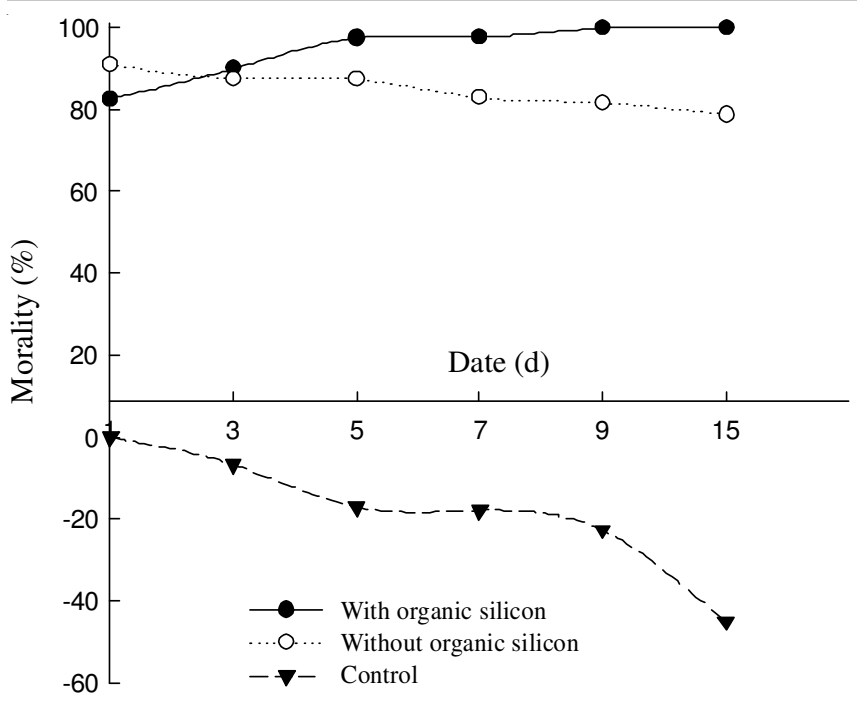

Fig. 2. Control effects of the mixtures of $50 \mathrm{mg} \mathrm{L}^{-1}$ imidacloprid with 0.06 $\%$ organic silicon against the solenopsis mealybug on the plants of T. fournieri. The value of mortality less than zero indicates the increasing of solenopsis mealybug population

\section{REFERENCES}

1. M. Knoche, Weed Res., 34, 221 (1994).

2. F.J. Deng, S.S. Cao and Y.Q. Wen, Chem. Res. Appl., 14, 723 (2002).

3. J.D. Tinsley, Can. Entomol., 30, 47 (1898).

4. G. Abbas, M.J. Arif and S. Saeed, Pakistan Entomol., 27, 83 (2005).

5. M. Yousuf, M. Tayyib and S. Shazia, Pakistan Entomol., 29, 49 (2007).

6. C.J. Hodgson, G. Abbas, M.J. Arif, S. Saeed and H. Karar, Zootaxa, 1913, 1 (2008).

7. K. Charleston and D. Murray, Available at http://thebeatsheet.com.au/ mealybugs (2010).

8. V.S. Nagrare, S. Kranthi, V.K. Biradar, N.N. Zade, V. Sangode, G. Kakde, R.M. Shukla, D. Shivare, B.M. Khadi and K.R. Kranth, Bull. Entomol. Res., 99, 537 (2009).

9. A. Muhammad, Available at http://agroict.org/adss/MealyBug_Report. aspx (2007).

10. Y.P. Wang, G.W. Watson and R.Z. Zhang, Agric. Forest Entomol., 12, 403 (2010) 